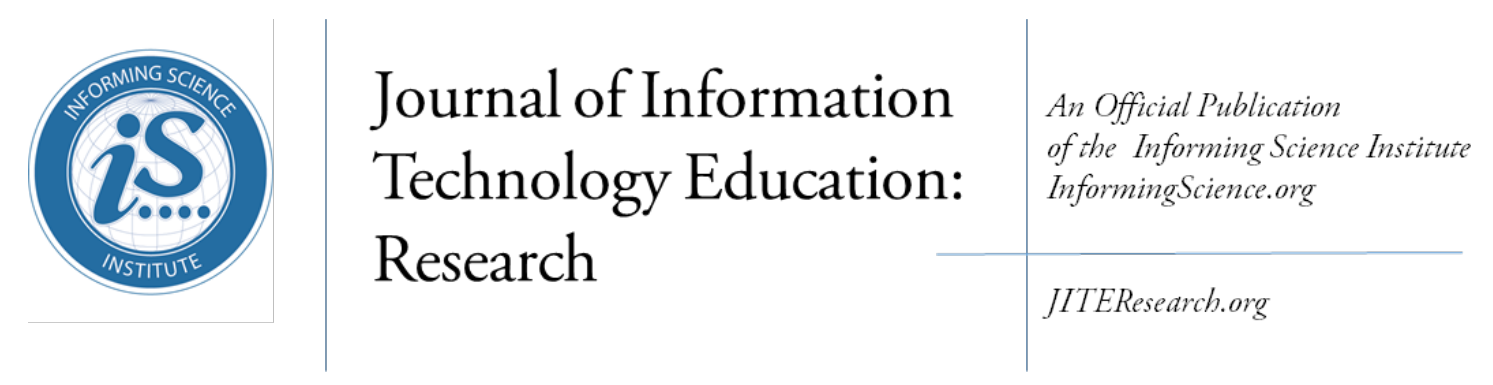

Volume 17, 2018

\title{
THE Role OF Motivation IN THE USE OF LECTURE BEHAVIORS IN THE ONLINE CLASSROOM
}

\author{
Mik Fanguy \\ Jamie Costley* \\ Christopher Lange \\ Matthew Baldwin
}

Seunglock Han

* Corresponding author
Korea Advanced Institute of Science mik@kaist.edu and Technology (KAIST), Daejeon, South Korea

Kongju National University, Gongju, costleyjamie@gmail.com South Korea

Dankook University, Yongin, South christopherhlange@gmail.com Korea

Korea Advanced Institute of Science mbaldwin@,kaist.ac.kr and Technology (KAIST), Daejeon, South Korea

Kongju National University, Gongju, hsrcom@kongju.ac.kr South Korea

\section{ABSTRACT}

Aim/Purpose

Extant research provides conflicting information regarding the role that lecture behaviors play within e-learning lectures. This study sought to understand what role motivation plays in increasing the likelihood that students engage in lecture behaviors in general, and how motivation affects the differing types of lecture behaviors.

Background The growth of online learning has increased the importance of video lectures as a means of delivering content. As with offline lectures, students may find it useful to adapt and change the way they interact with lectures to improve their learning. One possible approach that allows students to effectively manage any challenges they have in understanding a lesson is to initiate lecture behaviors to alter the flow of information.

Methodology In the present study, a survey was administered to cyber university students ( $\mathrm{n}=$ $2434)$ in order to examine at the relationship between intrinsic goal orientation (a type of motivation) and levels of lecture behaviors.

Accepted by Editor Tian Luo | Received: June 25, 2018 | Revised: August 29, September 19, October 1, 2018 | Accepted: October 8, 2018.

Cite as: Fanguy, M. Costley, J., Lange, C., Baldwin, M. \& Han, S. (2018). The role of motivation in the use of lecture behaviors in the online classroom. Journal of Information Technology Education: Research, 17, 471-484. https://doi.org/10.28945/4131

(CC BY-NC 4.0) This article is licensed to you under a Creative Commons Attribution-NonCommercial 4.0 International License. When you copy and redistribute this paper in full or in part, you need to provide proper attribution to it to ensure that others can later locate this work (and to ensure that others do not accuse you of plagiarism). You may (and we encourage you to) adapt, remix, transform, and build upon the material for any non-commercial purposes. This license does not permit you to use this material for commercial purposes. 
Contribution This research fills an important gap by showing the effects that motivation can have on how students interact with video lectures and suggests the ways in which students engaging in specific lecture behaviors do so in order to gain a better understanding of the content. As lecture behaviors are an important part of how students are interacting with this important and new method of teaching, it is important to understand which characteristics make students more likely to engage in lecture behaviors.

Findings Students who have higher levels of motivation are more likely to engage in lecture behaviors. These lecture behaviors may include splitting attention between media sources, pausing the video lecture, rewatching parts of the video lecture, and diverting attention to obtain better audio or visual clarity.

Recommendations Instead of just tracking students' viewing progress on each course lecture video, for Practitioners instructors should further endeavor to measure their students' use lecture behaviors in relation to online course lecture content. Doing so can provide valuable insight into students' level of engagement with course lecture materials and overall levels of intrinsic goal orientation.

Recommendations Researchers need to start factoring in how student characteristics interact with for Researchers instructional engagement when investigating online learning.

Impact on Society Improvement in our understanding of online learning helps improve the quality of instruction, which provides a net gain for society.

Future Research This paper is a broad overview using a survey, so future research should focus on a more detailed analysis of lecture behaviors, possibly using controlled experiments.

Keywords $\quad$ cyber university; intrinsic goal orientation; Korea; lecture behaviors; motivation; online learning

\section{INTRODUCTION}

E-learning has been viewed by universities as a potential means of offering high-quality education as enrollment and budgets decline (H. S. Lee \& Lee, 2015). Likewise, students themselves recognize the advantages of online learning, including a wide variety of course offerings and flexibility in scheduling and pacing (Parsad, Lewis, \& Tice, 2008). As the use of online learning environments increases worldwide, the clear delivery of course contents to students is an important consideration, particularly since lack of interest and motivation have been commonly reported in e-learning situations $(\mathrm{H}$. J. Lee \& Rha, 2009; Russo \& Benson, 2005). Online lecture videos are an important component of many e-learning environments, as they enable students to access lecture contents at any time. When students experience feelings of confusion while watching course lecture videos, they may exhibit a variety of lecture behaviors in order to increase their comprehension. These behaviors can include pausing, scrolling backward or forward in order to rewatch or skip contents, increasing the playback speed of the video, looking away from the video in order to listen carefully, dividing attention between text and visuals, and temporarily ceasing to listen in order to focus on the video screen.

Another term that is highly related to lecture behaviors in the literature is learner-controlled pacing, which refers to learning environments in which students can exert control over the pacing and flow of course content (Williams, 1993). In courses that utilize online lecture videos, learner-controlled pacing means that students are provided with options such as pausing, repeating, and accelerating and decelerating playback speed while watching video instruction. Studies have demonstrated that learner-controlled pacing benefits learning and that it may be a successful approach to learning the course content (Mayer \& Chandler 2001; Mayer, in Tabbers \& de Koeijer, 2010). Schwan and Riempp (2004) showed that in courses that enable learner-controlled pacing, students to gain a deeper under- 
standing of course content than if learner-controlled pacing is not enabled. Another factor that may affect how students behave in online learning environments is intrinsic motivation (Martens, Gulikerst, \& Bastiaens, 2004). This is because high levels of intrinsic motivation result in complex processing by students as they endeavor to understand more complex content as an end in itself, rather than for any external reward (Pintrich, 1991). Intrinsically motivated students are more likely to set goals that may ultimately determine how they engage the course material (Meece, Blumenfeld, \& Hoyle, 1988). Intrinsic goal orientation (IGO) refers to the internal motivations for learning as they relate to goal setting. IGO refers to the internally-driven motivation of the student to achieve their general course goals (Pintrich, 1991). When students have high levels of IGO, they are more likely to engage in the learning process due to a sense of challenge, curiosity, or mastery (Pintrich, 1991). Considering that intrinsically motivated students are more likely to implement more successful strategies to achieve their learning goals, and given the wide variety of approaches to and rates of success with using lecture behaviors while watching course videos online, it is worthwhile to examine the role of IGO on students' use of lecture behaviors while watching online course videos. Therefore, the present study presents the results of a survey given to the students of a cyber university in South Korea $(\mathrm{n}=2434)$ in order to examine at the relationship between IGO and students' use of lecture behaviors.

\section{LITERATURE REVIEW}

\section{THE ROLE OF MOTIVATION IN E-LEARNING}

According to a meta-analysis by Payne, Youngcourt and Beaubien (2007), studies have shown that learners who display mastery goal orientation are more successful with regards to learning the course content. High levels of IGO indicate that the learner is aiming to gain a deeper understanding of specific activities and tasks (Lyke \& Kelaher Young, 2006). This reflects the attitude of sustained perseverance toward learning that is associated with IGO (Vansteenkiste, Lens, \& Deci, 2006). The manner in which intrinsically motivated learners cognitively process information may enable them to better understand course content and increase learning. Increased levels of learning can be achieved when learners utilize unoccupied space in their working memory to set goals (Granger, 2012). Evidence of this can be found in cognitive behavior modification, where goal-setting is part of the change in a learner's cognitive processes (Stipek, 1996). Moreover, the implementation of learners' specific goal orientation affects their motivation, cognition, and achievement (Wolters, 2004). Pintrich and DeGroot (1990) provided further evidence of this by showing a connection between IGO and the implementation of specific cognitive strategies used to increase learning. Ultimately, motivation is seen as an indicator of learners' cognitive processing (Sins, van Joolingen, Savelsbergh, \& van HoutWolters, 2008). In the rather autonomous context of e-learning, the motivation levels of students have been shown to affect levels of germane load and to play an important role in students' achievement. M. K. Lee, Cheung, and Chen reported that intrinsic motivation (perceived enjoyment) significantly affected students' intention to engage in an internet-based learning medium. Zusho, Pintrich, and Coppola (2003) found that high academic achievers had increased levels of motivation in the forms of subjective feelings of self-efficacy and task value.

As certain behavioral responses to lectures apply only to video (e.g., pausing and scrolling backward and forward) and not to traditional classroom lectures, it would seem that online video lectures provide advantages in allowing students to control the pace and flow of content (Schwan \& Riempp, 2004). Furthermore, lecture behaviors help mitigate the negative correlation between certain types of poor instruction and student learning (Costley, Fanguy, Baldwin, \& Lange, 2017). However, some studies have shown that lecture behaviors may increase extraneous cognitive load, thereby impeding comprehension. For example, when attention is split between separated sources within a video lecture, extraneous cognitive processing by students can be increased (Kizilcec, Bailenson, \& Gomez, 2015; Mayer \& Moreno, 2003). Caspi, Gorsky, and Privman (2005) reported that even short pauses 
while viewing online lectures interrupted the context of the instruction being given. Kalyuga (2008) noted that less proficient learners may experience additional cognitive burden when faced with the option of controlling the pace of a video lecture. Moreno and Valdez (2005) and Tabbers, Martens, and van Merriënboer (2004) reported that learner-controlled pacing provided no benefit compared to system-controlled pacing (in which learners view instructional videos without the ability to regulate the pace). Le, Joordens, Chrysostomou, and Grinnell (2010) found that learners who used lecture behaviors most often when watching lecture videos exhibited the worst performance, which casts doubt upon the efficacy of lecture behaviors as a learning strategy. Le et al. (2010) also reported increased lecture behaviors in learners who implemented a surface strategy to learning, which is an approach that is driven by extrinsic motivation, where the student attempts to avoid failure while spending as little time and effort as possible (resulting in rote learning). In that study, the researchers found that pausing the video was negatively correlated with course grade point average (Le et al., 2010).

However, claims of the ineffectiveness of lecture behaviors as a learning strategy should be considered in light of evidence that they are beneficial. Kim et al. (2014) pointed out that action peaks in interaction data - where a large number of learners exhibit lecture behaviors during a specific time period - may be caused by the learners' level of interest or perceived importance of the topic rather than by confusion with the topic. Veletsianos, Pasquini, and Reich (2016) reported a strategy of rewatching videos at a different playback rate in order to review main points and increase note-taking, while Bruff, Fisher, McEwen, and Smith (2013) noted that learners may believe that increasing the video playback rate would help to increase focus and learning from the lecture. According to Budin (2016), pausing may be part of learning strategy if the learner uses the time to encode meaningful amounts of information (Ruhl, Hughes, \& Schloss, 1995 in Budin, 2016). Additionally, Cardall, Krupat, and Ulrich (2008) found that all 204 respondents who were surveyed had viewed video lectures and that the majority of respondents had increased the playback rate of the videos and indicated that this behavior was beneficial to their learning. Owston, Lupshenyuk, and Wideman (2011) noted that proficient students often skip ahead to specific sections and view these sections only once. This behavior is contrasted by that of less proficient students, who usually watched the entire videos from start to finish. The work of von Konsky, Ivins, and Gribble (2009) showed a similar result, with proficiency being associated with watching less of the video lecture contents as well as a tendency to watch particular sections rather than entire videos, while low proficiency was associated with a tendency to view the videos in their entirety.

\section{MOTIVATION AND LECTURE BEHAVIORS}

The act of watching an online lecture video can perhaps, in and of itself, be considered a sign of course engagement, with estimates in the literature suggesting that only $50 \%$ of the students watch all videos in e-learning settings (Costley, Hughes, \& Lange, 2017). For this reason, lecture behaviors have often been viewed as signals of further student engagement in learning processes relevant to course materials. Kim et al. (2014) noted that lecture behaviors at certain points in a video may be caused by student interest in that topic or by the perceived importance of that subject to the viewer. Veletsianos et al. (2016) reported a learner strategy of viewing videos a second time with adjusted speed in order to review points and take more complete notes. Bruff et al. (2013) mentioned a learner who explained that increasing the playback rate of a lecture video would enable him or her to "stay focused" and gain more information from the stimulus. Referring to Berliner (1987, in Budin, 2016), Budin noted that pauses increase learner engagement and possibly performance.

Research shows that the level to which students are cognitively engaged is an important determiner of student participation. However, not all lecture behaviors represent engagement with the course material, and, in fact, some may indicate the opposite. Students' appetitive and aversive motivational systems, which motivate "approach" or "avoidance" behaviors, respectively, influence the level of cognitive processing when students are exposed to motivationally-relevant stimuli. Sinha, Jermann, Li, and Dillenbourg (2014) pointed out that in e-learning contexts, the goal of the appetitive system is 
acquiring information and exploring topics in depth and the aversive system primarily motivates avoidance of certain parts of the video instruction. Thus, Sinha et al. (2014) go on to describe click behaviors of the appetitive motivational systems as rewatching, seeking and scrolling back to clear up confusing concepts, and decreasing the playback speed, while click behaviors representing the aversive motivational system are skipping and increasing the playback speed. In a study on the effects of learner-controlled pacing while watching an instructional animated slide show, Tabbers and de Koeijer (2010) found that students' desire to learn more about the topic being covered had no effect on the amount of interaction behaviors (analogous with lecture behaviors, in this case) they exhibited while viewing the slides.

\section{THE CURRENT STUDY}

The present research examined students taking classes at the Open Cyber University (OCU) in South Korea, which offers credit classes online for students enrolled in any of the 23 brick-and-mortar universities that comprise the OCU consortium. The OCU is presently the largest cyber university in the nation, with about 120,000 students enrolled in approximately 400 classes (Open Cyber University, n.d.). Appetitive lecture behaviors represent an earnest attempt by the learner to comprehend the instruction content (Sinha et al., 2014). Levels of IGO have been shown to benefit student learning, as more motivated learners are more likely to attempt to master the contents, thereby increasing levels of learning (Payne et al., 2007). In particular, high levels of IGO are predictors of increased cognitive processing of students (Sins et al., 2008). The work of Costley et al. (2017) showed that appetitive lecture behaviors provide students with an important benefit in navigating confusing content in lecture videos, as lecture behaviors mitigate the negative correlation between extraneous load and germane load. Considering the effects of both lecture behaviors and motivation on learning, it is worthwhile to attempt to understand the relationship between these two factors. Therefore, the present research examines the following hypotheses:

\section{Research Hypotheses}

1. Motivation is positively correlated with appetitive lecture behaviors in total.

2. Motivation is positively correlated with the constituent parts that make-up the lecture behavior construct.

\section{METHODS}

\section{RESEARCH PROCEDURES, DATA COLLECTION, AND PARTICIPANTS}

To initially understand the nature of learning in the OCU, this research project started with brief interviews with students $(n=10)$ alone, in pairs, or in groups of 3 . While the questions were openended about the learners' experience using the OCU, there was a slight focus on the nature of learner-to-learner interaction as a part of their classes. In relation to this, students generally answered that there was a lack of interaction or learning activities as a part of the OCU, and that video lectures were the focal point of learning and instruction. For this reason, a survey was designed asking students $(\mathrm{n}=92)$ about the OCU's automated feedback systems, instructional design, and video lectures. This survey showed that there were important relationships between student learning and various aspects of the OCU's learning systems so a more detailed survey was devised to be given to a larger portion of the OCU's student base. This survey, which is used for this research, is more focused in its contents, dealing more directly with how students utilize the OCU's video lectures and how that affects their learning.

This survey was written first in English and then translated into Korean, the language used in the OCU, by a native speaker of Korean who is knowledgeable regarding e-learning. That translation was also checked by someone experienced with both online learning and the OCU and was found to be accurate. Therefore, a Google Sheets form was created containing the items and sent to the OCU's 
administrative offices. They also checked whether the survey was acceptable for the students to participate in and then posted a link on their main board inviting students to fill out the survey. The survey was active for one month and was subsequently taken down.

The participants in this survey filled out a survey using Google Sheets. 2689 students filled out the survey; however, $255 \mathrm{did}$ not complete all parts of the survey that were pertinent to this research project, leaving 2434 complete surveys. Of the 2434, 1241 (51\%) were female and 1193 (49\%) were male. The average age of the subjects that were part of this study was 23.6, with a standard deviation of 3.4. The oldest participant was 63, and the youngest was 19. In looking into other research on OCU, similar distributions of gender and age have been found (Suh \& Kim, 2013). Among the participants in this research program, a wide variety of classes were taken. The breakdown of these classes has been found to be similar to other research into the OCU (Kobayashi \& Kim, 2010).

\section{INSTRUMENT DEVELOPMENT}

The Motivated Strategies for Learning Questionnaire (MSLQ) is used to evaluate college students' motivational orientations and their use of different learning strategies (Pintrich, 1991). One part of this was used for the items to measure IGO. The items were Likert-type scales with a range from 1 to 7, with 1 being labeled "strongly disagree" and 7 being labeled "strongly agree". The MSLQ contains a collection of constructs designed to measure students' levels of motivation and use of learning strategies. From the MSLQ, four items were used in this study to measure IGO: (1) In a class like this, I prefer course material that really challenges me so I can learn new things; (2) In a class like this, I prefer course material that arouses my curiosity, even if it is difficult to learn; (3) The most satisfying thing for me in this course is trying to understand the content as thoroughly as possible; and (4) When I have the opportunity in this class, I choose course assignments that I can learn from even if they don't guarantee a good grade. The Cronbach's Alpha for this construct was .833, which is appropriate for this type of research.

To establish the lecture behaviors that would be measured for this study, the help of five of the students involved in the initial interviews was enlisted. A brief discussion covered likely behaviors they might engage in to improve their comprehension of the video lectures. Five items were generated from this discussion which were (1) I had to scan my eyes back and forth between the text and the graphs/images in the videos I watched; (2) I sometimes had to pause the video to read something on the PPT/whiteboard; (3) I had to rewatch some parts of the lecture to fully understand it; (4) I sometimes had to look away from the screen to listen more carefully; and (5) I sometimes had to stop listening to focus on something on the screen. In the present study, these items were presented as Likert-like, and participants were asked to score how strongly they agreed with the statements between 1 and 7. The Cronbach's Alpha was calculated for the combined construct at .878, which is appropriate for this type of research, and for a newly created construct.

\section{RESULTS}

To get an overview of the main variables used in this research, descriptive statistics for IGO, combined lecture behavior, and the constituent indicators that make up the lecture behavior construct are shown in Table 1. All of the variables had a minimum value of 1 and a maximum value of 7 , with a mean of 3.94 for IGO and 4.48 for lecture behaviors. Among the lecture behavior indicators, the means were similar, though the indicator with the highest mean (and therefore likely the most common) was I had to rewatch some parts of the lecture to fully understand it (5.59), second was I had to scan my eyes back and forth between the text and the graphs/images in the videos I watched (4.58), third was I sometimes had to pause the video to read something on the PPT/whiteboard (5.52), fourth was I sometimes had to stop listening to focus on something on the screen (4.51), and the indicator with the lowest mean was I sometimes had to look away from the screen to listen more carefully (4.22). 
Table 1. Descriptive statistics for the main variables

\begin{tabular}{|l|l|l|l|l|l|}
\hline & $\mathrm{N}$ & Min & Max & Mean & SD \\
\hline Intrinsic Goal Orientation & 2434 & 1 & 7 & 3.94 & 1.26 \\
\hline Lecture behavior & 2434 & 1 & 7 & 4.48 & 1.17 \\
\hline $\begin{array}{l}\text { Scan my eyes between the } \\
\text { text and graphs/images }\end{array}$ & 2434 & 1 & 7 & 4.58 & 1.42 \\
\hline \begin{tabular}{l} 
Pause to read something \\
\hline
\end{tabular} & 2042 & 1 & 7 & 4.52 & 1.52 \\
\hline
\end{tabular}

To understand the research questions that were a part of this research, Pearson's bivariate correlations were used. As shown in Table 2, there is a positive statistically significant relationship between IGO and lecture behavior (.371). This relationship had p-values of <.01. Also shown in Table 2 is the relationship between age and gender (-.307), revealing that men are older than women in the OCU, which is likely because Korean males are forced to serve two years in the military, which they often complete before they start university study or after their freshman year is finished. There are also small but statistically significant relationships between IGO and gender (-.105), which means males have a higher level of IGO, and between IGO and age (.071), showing that older students have higher levels of IGO. Also, there was a statistically significant relationship between age and lecture behavior (.70), showing that older students are more likely to engage in lecture behavior.

Table 2. Correlations between the main variables $(n=2434)$

\begin{tabular}{|c|c|c|c|c|}
\hline & Age & Gender & $\begin{array}{l}\text { Intrinsic Goal } \\
\text { Orientation }\end{array}$ & $\begin{array}{l}\text { Lecture } \\
\text { Behavior }\end{array}$ \\
\hline Age & 1 & & & \\
\hline Gender & $-.307 * *$ & 1 & & \\
\hline Intrinsic Goal Orientation & $.071 * *$ & $-.105^{* *}$ & 1 & \\
\hline Lecture Behavior & $.070 * *$ & 0.004 & $.371 * *$ & 1 \\
\hline
\end{tabular}

The relationship between indicators used to generate the lecture behavior construct and IGO can be seen in Table 3. All 5 indicators have a strong statistically significant relationship with IGO. The indicator with the highest correlation with IGO was I had to scan my eyes back and forth between the text and the graphs/images in the videos I watched (.358), followed by I sometimes had to stop listening to focus on something on the screen (.321), with I sometimes had to look away from the screen to listen more carefully (.285) third, fourth being I had to rewatch some parts of the lecture to fully understand it (.283), and the indicator with the lowest correlation with IGO was I sometimes had to pause the video to read something on the PPT/whiteboard (.260). 
Table 3. Correlations between intrinsic goal orientation and the individual lecture behaviors $(n=2434)$

\begin{tabular}{|c|c|c|c|c|c|c|}
\hline & 1 & 2 & 3 & 4 & 5 & 6 \\
\hline $\begin{array}{l}1 \text { Intrinsic Goal Orienta- } \\
\text { tion }\end{array}$ & 1 & & & & & \\
\hline $\begin{array}{l}2 \text { Scan my eyes between the } \\
\text { text and graphs/images }\end{array}$ & $.358^{* *}$ & 1 & & & & \\
\hline 3 Pause to read something & $.260^{* *}$ & $.493 * *$ & 1 & & & \\
\hline $\begin{array}{l}4 \text { Rewatch to fully under- } \\
\text { stand }\end{array}$ & $.283^{* *}$ & $.520^{* *}$ & $.764 * *$ & 1 & & \\
\hline $\begin{array}{l}5 \text { Look away from the } \\
\text { screen to listen }\end{array}$ & $.285^{* *}$ & $.452^{* *}$ & $.498^{* *}$ & $.549 * *$ & 1 & \\
\hline $\begin{array}{l}6 \text { Stop listening to focus on } \\
\text { the screen }\end{array}$ & $.321 * *$ & $.549 * *$ & $.630^{* *}$ & $.681^{* *}$ & $.566^{*}$ & 1 \\
\hline
\end{tabular}

\section{DISCUSSION}

The survey responses collected in the present study show a strong relationship between IGO and each of the appetitive lecture behaviors examined. These results indicate that more motivated students utilize lecture behaviors more frequently as part of their learning strategies in e-learning environments and that lecture behaviors may be viewed as a signal of a learner's willingness to engage with and understand the content being presented in a lecture video. The present results contradict those of Tabbers and de Koeijer (2010), who found no relationship between students' desire to learn more about a topic and the amount of lecture behaviors they exhibited while viewing media. Prior work has suggested that students prefer to have the option to exhibit lecture behaviors while watching course videos (i.e., learner-controlled pacing) and that doing so helps keep them focused and engaged, which may be considered aspects of motivation (Galbraith, 2004). Considering that the results of the present study show that the most motivated students exhibit lecture behaviors most frequently, it seems that there is a very clear link between motivation and lecture behaviors. Taken together, these results suggest the possibility of a virtuous cycle of learner-controlled pacing increasing motivation, and increased motivation leading to a greater number of lecture behaviors being implemented.

Among the five lecture behaviors examined in the present study, the three behaviors that showed the strongest correlation with IGO were scanning the eyes back and forth between text and images, cessation of viewing in order to listen carefully to the lecture, and cessation of listening to focus on something on the screen. Interestingly, these three behaviors are not particular to e-learning environments and may be applied in traditional classrooms as well. A possible explanation for this is that, as IGO has been found to be positively correlated with the ability to select successful learning strategies (Nevgi, 2001; Svinicki, 2005), more motivated students may have successfully used these lecture behaviors in their traditional classroom environments and simply transferred them to a new elearning environment. Perhaps the slightly lower correlation between students with higher levels of IGO and video-specific lecture behaviors could be due to less familiarity with the online learning environment since, given the dominance of traditional classroom environments in pre-university education, such students would have received the vast majority of their education in brick-and-mortar classrooms. 
There were correlations found between lecture behaviors and IGO, but there were also strong correlations among individual lecture behaviors. More specifically, the constituent behaviors that made up the lecture behavior construct were strongly correlated with each other. Among these, the relationship between pausing the video and rewatching was especially clear. As discussed in the work of Kim et al. (2014) and Li, Kidzinski, Jermann, and Dillenbourg (2015), frequent pausing is often a sign of confusion, and prior research has shown that students who have a difficult time understanding the content of a video are more likely to rewatch (Le et al., 2010; Lin et al., 2016). Strong correlations were additionally shown between cessation of viewing the video to listen carefully to the lecture and to rewatching the video. Cessation of listening in order to focus on some visual aspects of the slide was correlated most strongly with rewatching and pausing the video. Such correlations seem reasonable, as confusion when listening to an audio medium is likely to induce replaying the stimulus for clarity, as pausing the video essentially removes the audio element while freezing the visuals on the screen. On the other hand, when confused by visual elements on the screen, pausing enables students to continue to view the visuals on the slide without the distraction of audio, before replaying the section for final clarification. Cessation of listening to focus on visuals was also strongly related with scanning one's eyes between text and visuals. The need to scan one's eyes between text and images may indicate visual overload on the part of the learner, and cessation of listening to the audio may be a coping mechanism to enable greater focus on the confusing aspect of the stimulus.

\section{CONCLUSION}

The present study has examined the relationship between IGO, which has been shown to be a strong predictor of student success in e-learning environments, and appetitive lecture behaviors, which have often been shown in the literature to be a successful learning strategy. Through analysis of survey response data collected from 2434 students enrolled in South Korea's OCU, a strong positive correlation was found between students' levels of IGO and their use of lecture behaviors, suggesting that lecture behaviors may be considered as a sign of student engagement with the course content. Moreover, even stronger correlations were found among individual lecture behaviors, suggesting that students tend to use such behaviors in concert as part of an active learning strategy.

There are several implications of these findings. The first is that instead of just tracking students' viewing progress on each course lecture video, instructors should further endeavor to measure their students' use lecture behaviors in relation to online course lecture content. This can be done through collecting self-reported survey data, as was done in the present study, through direct observation of students viewing video content, or through analyzing clickstream data (the tracking of individual mouse clicks performed within the viewing window), if such information is available. Data on students' use of lecture behaviors can provide valuable insight into students' level of engagement with course lecture materials and overall levels of IGO. Considering that highly motivated students tend to be more successful at learning and the positive correlation between IGO and lecture behaviors found in this study, lecture behaviors are likely to be a successful learning strategy in e-learning contexts. Furthermore, the lecture behaviors examined herein have been shown in a previous study to be positively correlated with germane load and to mitigate the negative correlation between extraneous and germane load (Costley et al., 2017). Therefore, it is reasonable that instructors should seek to encourage the use of lecture behaviors in students who tend not use them, just as instructors may seek to increase other types of appetitive lecture behaviors during traditional lectures, such as note taking, asking and responding to questions, and eye contact. As e-learning is still a relatively new mode of instruction and many students may still be unfamiliar with it, instruction on effective use of lecture behaviors while watching course videos could help to increase student engagement in the course and learning outcomes as well.

Although the findings of the present study are valuable to instructors and content creators in elearning contexts, several limitations must be noted. The first of these is the use of self-reported information on students' use of lecture behaviors. Such self-reported data indicates whether or not 
students engaged in lecture behaviors and what types of behaviors they employed. However, clickstream data, which has been used in a number of studies (Guo, Kim, \& Rubin, 2014; Kim et al, 2014; Le et al. 2010; Li et al. 2015), provides more detailed insights into how and when lecture behaviors are used. Unfortunately, clickstream data from the OCU was unavailable. Another possible limitation of the present study is that the subjects were pooled from a homogenous population in South Korea. South Korea has the highest bandwidth per person of any nation in the world (Tan, 2016), and it may be reasonably assumed that the population is more familiar with the usage of computers and the internet than citizens of nations with less developed economies or technical infrastructures. It is, therefore, possible that the relatively high level of familiarity and comfort with online environments may have predisposed the South Korean students to engage in a higher number of lecture behaviors. For this reason, it would be interesting to examine how familiarity with online environments affects the relationship between IGO and lecture behaviors, especially in regions with less developed IT infrastructures.

\section{REFERENCES}

Bruff, D. O., Fisher, D. H., McEwen, K. E., \& Smith, B. E. (2013). Wrapping a MOOC: Student perceptions of an experiment in blended learning. Journal of Online Learning and Teaching, 9(2), 187-199. Retrieved from https://my.vanderbilt.edu/douglasfisher/files/2013/06/JOLTPaperFinal6-9-2013.pdf

Budin, S. (2016). Stop and pause for engagement in online video lectures. In B. Chen, A. deNoyelles, \& K. Thompson (Eds.), Teaching online pedagogical repository. Orlando, FL: University of Central Florida Center for Distributed Learning. Retrieved from https://topr.online.ucf.edu/stop-and-pause-for-engagement-inonline-video-lectures/

Cardall, S., Krupat, E., \& Ulrich, M. (2008). Live lecture versus video-recorded lecture: Are students voting with their feet? Academic Medicine, 83(12), 1174-1178. https://doi.org/10.1146/annurev.psych.50.1.191

Caspi, A., Gorsky, P., \& Privman, M. (2005). Viewing comprehension: Students' learning preferences and strategies when studying from video. Instructional Science, 33(1), 31-47. https://doi.org/10.1007/s11251-0042576-x

Costley, J., Fanguy, M., Baldwin, M., \& Lange, C. (2017). The mediating effects of lecture behaviors on the relationship between extraneous load and germane load. Manuscript submitted for publication.

Costley, J., Hughes, C. \& Lange, C. (2017). The effects of instructional design on beginning to watch and completing video lectures at cyber universities. Journal of Information Technology Education: Research, 16, 189 - 207. https://doi.org/10.28945/3728

Galbraith, J. (2004, August). Active viewing: An oxymoron in video-based instruction? Paper presented at the 2004 Society for Applied Learning Technologies Conference (SALT), Arlington, VA. Retrieved from http://designer.50g.com/docs/Salt 2004.pdf

Granger, B. P. (2012). Enhancing training outcomes in the context of e-learning: The impact of objective learner control, training content complexity, cognitive load, learning goal orientation, and metacognitive strategies (Doctoral dissertation, University of South Florida). Retrieved from http://scholarcommons.usf.edu/etd/4326

Guo, P. J., Kim, J., \& Rubin, R. (2014, March). How video production affects student engagement: An empirical study of MOOC videos. In Proceedings of the First ACM Conference on Learning@ Scale Conference (pp. 41-50). New York, NY: ACM. https://doi.org/10.1145/2556325.2566239

Kalyuga, S. (2008). Relative effectiveness of animated and static diagrams: An effect of learner prior knowledge. Computers in Human Behavior, 24(3), 852-861. https://doi.org/10.1016/j.chb.2007.02.018

Kim, J., Guo, P. J., Seaton, D. T., Mitros, P., Gajos, K. Z., \& Miller, R. C. (2014, March). Understanding in-video dropouts and interaction peaks in online lecture videos. In Proceedings of the first ACM conference on Learning@scale conference (pp. 31-40). New York, NY: ACM. https://doi.org/10.1145/2556325.2566237

Kizilcec, R. F., Bailenson, J. N., \& Gomez, C. J. (2015). The instructor's face in video instruction: Evidence from two large-scale field studies. Journal of Educational Psychology, 107(3), 724-739. https://doi.org/10.1037/edu0000013 
Kobayashi, T. \& Kim, Y. (2010). The status of cyber education in Korean higher learning: The potential for East Asian linkage in higher education. The Open University of Japan Repository. Retrieved from http://id.nii.ac.jp/1146/00003502/

Le, A., Joordens, S., Chrysostomou, S. \& Grinnell, R. (2010). Online lecture accessibility and its influence on performance in skills-based courses, Computers and Education 55, 313-319. https://doi.org/10.1016/i.compedu.2010.01.017

Lee, H. J., \& Rha, I. (2009). Influence of structure and interaction on student achievement and satisfaction in web-based distance learning. Educational Technology \& Society, 12(4), 372-382. Retrieved from https://www.jstor.org/stable/jeductechsoci.12.4.372

Lee, H. S. \& Lee, S. Y. (2015). Analysis of various influences and factors on academic persistence of cyber university students. International Journal of Service, Science and Technology, 8(10), 211-222. https://doi.org/10.14257/ijunesst.2015.8.10.21

Lee, M. K., Cheung, C. M., \& Chen, Z. (2005). Acceptance of internet-based learning medium: The role of extrinsic and intrinsic motivation. Information \& Management, 42(8), 1095-1104. https://doi.org/10.1016/j.im.2003.10.007

Li, N., Kidzinski, L., Jermann, P., \& Dillenbourg, P. (2015, May). How do in-video interactions reflect perceived video difficulty? In Proceedings of the European MOOCs Stakeholder Summit 2015 (No. EPFL-CONF-207968, pp. 112-121). PAU Education. Retrieved from https://infoscience.epfl.ch/record/207968/

Lin, S. Y., Aiken, J. M., Seaton, D. T., Douglas, S. S., Greco, E. F., Thoms, B. D., \& Schatz, M. F. (2016). Exploring university students' engagement with online video lectures in a blended introductory mechanics course. Retrieved from https://arxiv.org/abs/1603.03348

Lyke, J. A., \& Kelaher Young, A. J. (2006). Cognition in context: Students' perceptions of classroom goal structures and reported cognitive strategy use in the college classroom. Research in Higher Education, 47(4), 477490. https://doi.org/10.1007/s11162-005-9004-1

Martens, R. L., Gulikerst, J., \& Bastiaens, T. (2004). The impact of intrinsic motivation on e-learning in authentic computer tasks. Journal of Computer Assisted Learning, 20(5), 368-376. https://doi.org/10.1111/j.13652729.2004.00096.x

Mayer, R. E., \& Chandler, P. (2001). When learning is just a click away: Does simple user interaction foster deeper understanding of multimedia messages? Journal of Educational Psychology, 93(2), 390-397. https://doi.org/10.1037/0022-0663.93.2.390

Mayer, R. E., \& Moreno, R. (2003). Nine ways to reduce cognitive load in multimedia learning. Educational Psychologist, 38(1), 43-52. https://doi.org/10.1207/S15326985EP3801 6

Meece, J. L., Blumenfeld, P. C., \& Hoyle, R. H. (1988). Students' goal orientations and cognitive engagement in classroom activities. Journal of Educational Psychology, 80(4), 514-523. https://doi.org/10.1037/0022$\underline{0663.80 .4 .514}$

Moreno, R., \& Valdez, A. (2005). Cognitive load and learning effects of having students organize pictures and words in multimedia environments: The role of student interactivity and feedback. Educational Technology Research and Development, 53(3), 35-45. https://doi.org/10.1007/BF02504796

Nevgi, A. (2001, July). Motivational strategies of students in Virtual University. In Third International, Interdisciplinary Evidence-Based Policies and Indicator Systems Conference (pp. 1-17). Retrieved from https://www.researchgate.net/publication/228383410 Motivational strategies of students in Virtual University

Open Cyber University. (n.d.). About OCU. Retrieved from http://en.ocu.ac.kr/Minfo.do?cmd=about\& $\underline{\text { menuGubunCode }=01}$

Owston, R., Lupshenyuk, D., \& Wideman, H. (2011). Lecture capture in large undergraduate classes: Student perceptions and academic performance. The Internet and Higher Education, 14(4), 262-268. https://doi.org/10.1016/j.iheduc.2011.05.006 
Parsad, B., Lewis, L., \& Tice, P. (2008). Distance education at degree-granting postsecondary institutions: 2006-2007. Washington, DC: National Center for Education Statistics, Institute of Education Sciences, US Department of Education. Retrieved from https://nces.ed.gov/pubsearch/pubsinfo.asp?pubid=2009044

Payne, S. C., Youngcourt, S. S., \& Beaubien, J. M. (2007). A meta-analytic examination of the goal orientation nomological net. Journal of Applied Psychology, 92(1), 128-150. https://doi.org/10.1037/0021-9010.92.1.128

Pintrich, P. R. (1991). A manual for the use of the motivated strategies for learning questionnaire (MSLQ). Retrieved from https:// files.eric.ed.gov/fulltext/ED338122.pdf

Pintrich, P. R., \& DeGroot, E. (1990, April). Quantitative and qualitative perspectives on student motivational beliefs and self-regulated learning. Paper presented at the Annual Meeting of the American Educational Research Association, Boston, MA.

Russo, T., \& Benson, S. (2005). Learning with invisible others: Perceptions of online presence and their relationship to cognitive and affective learning. Educational Technology \& Society, 8(1), 54-62. Retrieved from https://www.jstor.org/stable/jeductechsoci.8.1.54?seq=1\#page scan tab contents

Schwan, S., \& Riempp, R. (2004). The cognitive benefits of interactive videos: Learning to tie nautical knots. Learning and Instruction, 14(3), 293-305. https://doi.org/10.1016/j.learninstruc.2004.06.005

Sinha, T., Jermann, P., Li, N., \& Dillenbourg, P. (2014). Your click decides your fate: Inferring information processing and attrition behavior from MOOC video clickstream interactions. Retrieved from https://arxiv.org/abs/1407.7131

Sins, P. H., van Joolingen, W. R., Savelsbergh, E. R., \& van Hout-Wolters, B. (2008). Motivation and performance within a collaborative computer-based modeling task: Relations between students' achievement goal orientation, self-efficacy, cognitive processing, and achievement. Contemporary Educational Psychology, 33(1), 58-77. https://doi.org/10.1016/j.cedpsych.2006.12.004

Stipek, D. (1996). Motivation and instruction. In D. Berliner \& R. Calfee (Eds.), Handbook of educational psychology (pp. 85-113). Macmillan: New York.

Suh, S., \& Kim, S. (2013). Study on policy for an entrance quota of cyber universities. Seoul, Korea: Korea Educational Information and Research Service.

Svinicki, M. (2005). Student goal orientation, motivation, and learning. Idea Paper, 41. Retrieved from https://www.ideaedu.org/Portals/0/Uploads/Documents/IDEA\%20Papers/IDEA\%20Papers/Idea Pap er 41.pdf

Tabbers, H. K., \& de Koeijer, B. (2010). Learner control in animated multimedia instructions. Instructional Science, 38(5), 441-453. https://doi.org/10.1007/s11251-009-9119-4

Tabbers, H. K., Martens, R. L., \& Merriënboer, J. J. (2004). Multimedia instructions and cognitive load theory: Effects of modality and cueing. British Journal of Educational Psychology, 74(1), 71-81. https://doi.org/10.1348/000709904322848824

Tan, M. (2016). Turning point for a regime of rightlessness? In Y. Kim (Ed.), Routledge handbook of Korean culture and society (pp. 162-176). London and New York: Routledge.

Veletsianos, G., Reich, J., \& Pasquini, L. A. (2016). The life between big data log events: Learners' strategies to overcome challenges in MOOCs. AERA Open, 2(3), 1-10. https://doi.org/10.1177/2332858416657002

Vansteenkiste, M., Lens, W., \& Deci, E. L. (2006). Intrinsic versus extrinsic goal contents in self-determination theory: Another look at the quality of academic motivation. Educational Psychologist, 41(1), 19-31. https://doi.org/10.1207/s15326985ep4101 4

von Konsky, B. R., Ivins, J., \& Gribble, S. J. (2009). Lecture attendance and web based lecture technologies: A comparison of student perceptions and usage patterns. Australasian Journal of Educational Technology, 25(4), 581-595. https://doi.org/10.14742/ajet.1130

Williams, M. D. (1993). A comprehensive review of learner-control: The role of learner characteristics. In M. R. Simonson (Ed.), Proceedings of the Annual Conference of the Association for Educational Communications and Technology (pp. 1083-1114). New Orleans, LA: Association for Educational Communications and Technology. Retrieved from https://eric.ed.gov/?id=ED362144 
Wolters, C. A. (2004). Advancing achievement goal theory: Using goal structures and goal orientations to predict students' motivation, cognition, and achievement. Journal of Educational Psychology, 96(2), 236-250. https://doi.org/10.1037/0022-0663.96.2.236

Zusho, A., Pintrich, P. R., \& Coppola, B. (2003). Skill and will: The role of motivation and cognition in the learning of college chemistry. International Journal of Science Education, 25(9), 1081-1094.

https://doi.org/10.1080/0950069032000052207

\section{BIOGRAPHIES}

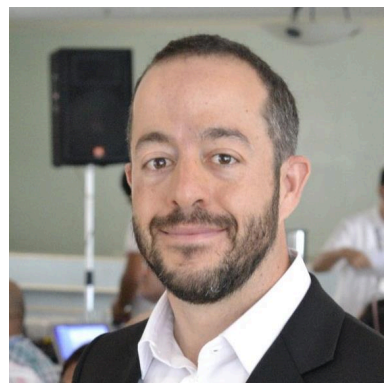

Mik Fanguy is a visiting professor in the English as a Foreign Language Program at the Korea Advanced Institute of Science and Technology (KAIST) in South Korea. His research interests include student lecture behaviors, online video lectures, and online learning.

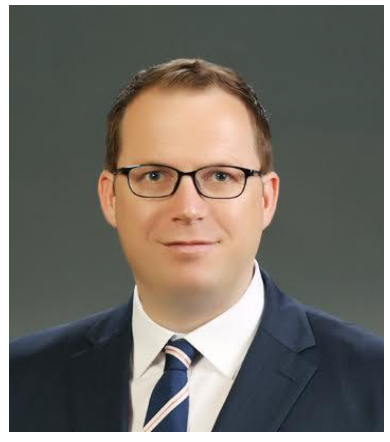

Jamie Costley is a visiting professor in the College of Education at Kongju National University, South Korea. His main area of research is the impact of task or learning environment design on student-to-student interaction. Dr. Costley is currently involved in research into improving instruction in online classes in South Korea.

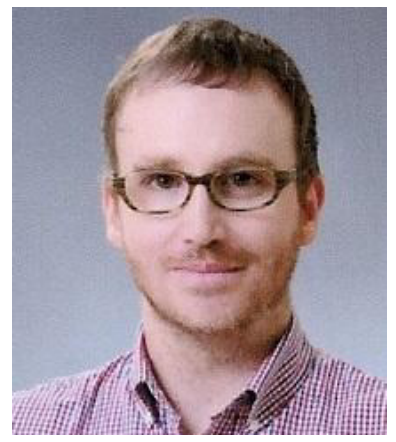

Christopher Lange is a visiting professor in the Department of British and American Humanities at Dankook University in South Korea. He has published papers on informal group work, e-learning instructional design, and the effects of learning strategies within online environments. His current research is focused on the effects of cognitive load and learner control within e-learning environments. Additionally, he is interested in investigating ways of improving online instruction, design, and delivery to better address the needs of e-learning students. He earned a PhD in Education from Kongju National University in South Korea in 2017. 


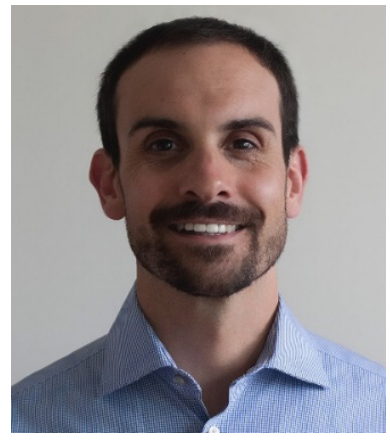

Matthew Baldwin is a visiting professor in the EFL department at the Korea Advanced Institute of Science and Technology (KAIST). He holds an MA in TESOL and a BA in English language and literature. His research interests include writing feedback, international education, and flipped class instruction.

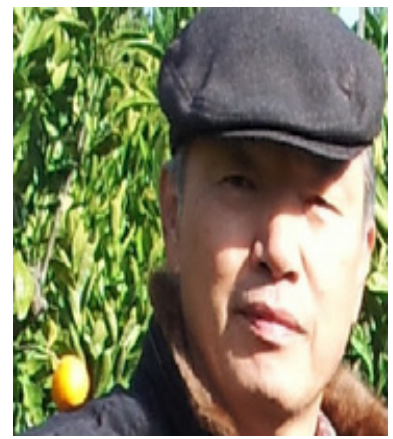

Dr. Han has been involved in research into instructional design for more than three decades. Since the increase in online learning in Korea, Dr.

Han has also been involved in research into how to assess and understand learning online. 